\title{
DocênciaS na/com a contemporaneidade: experiências (trans)formadoras em meio à cultura digital e em rede
}

\author{
Adriana Rocha Bruno* \\ Lucila Pesce**
}

\section{Resumo}

O presente artigo aborda as docênciaS na contemporaneidade, em meio à cultura digital e em rede. A multiplicidade, uma das marcas do mundo atual, convoca todos à distorção de olhares, maximização de percepçôes, escutas e odores, eclosão de paladares, para a vivência paradoxal, em dimensôes atemporais e pluriespaciais. O diverso e o plural coexistem e, assim, são contraditórios, complexos e também instigantes. Para falar/pensar em processos formativos, docência e discência, neste contexto faz-se necessário plurificar. Dessa forma, justifica-se a expressão docênciaS, com destaque para a letra $S$, plural, múltipla. Para tratar de um tema tão vasto e complexo, são apresentados três pontos de "flexão": 1) Oroboro: a persistência/insistência da docência apartada da discência; 2) a cultura digital e em rede: desdobrando ideias para a prática do desapego; 3) temas e dilemas atuantes como campo de possibilidades nas/com as docênciaS contemporâneas. Todos estes pontos são desenvolvidos/debatidos por meio das pesquisas que foram realizadas nos últimos anos, em articulação com as experiências de docências, agenciadas pelas investigaçôes sobre as práticas pedagógicas cocriadas na cibercultura.

Palavras-chave: Docências contemporâneas. Cultura digital. Experiências e redes.

* Doutora em Educação pela Pontifícia Universidade Católica de São Paulo (PUC/SP). Professora do Departamento de Educação e dos Programas de Pós-Graduação em Educação e em Gestão e Avaliação da Educação Pública da Universidade Federal de Juiz de Fora (UFJF).

** Doutora em Educaçáo pela Pontifícia Universidade Católica de São Paulo (PUC/SP). Professora do Departamento de Educação e do Programa de Pós-Graduação em Educação da Universidade Federal de São Paulo (UNIFESP). 


\section{Oroboro: a persistência e a insistência da docência apartada da discência}

Propomos ao leitor que mergulhe neste texto a partir da imagem do oroboro - a cobra/ou dragão que morde a própria cauda e remete à ideia de princípio-fim, circularidade, continuidade, infinitude. É desse modo que convidamos a todos, ao diálogo reflexivo sobre a docência no mundo atual, contemporâneo, que traz dentre os seus desdobramentos a compreensão de que vivemos em uma cultura que é ciber, é digital e que se constitui, também, pelo sentido de redes.

A docência, neste cenário, leva-nos a perceber o mundo múltiplo proclamado por Deleuze (2011) e, portanto, plural. A pluralidade em articulação com a multiplicidade projeta-nos a pensar-criar-fazer DocênciaS. Os devires que estes processos implicam erguem-se em meio a redes de circularidade não finita e não recursiva, de continuidade não linear e não fixa, de rizomas e não determinados, previsíveis, arbóreos.

Ororoboros! Sim. Uma metáfora para encararmos os processos de ensino e de aprendizagem que temos promovido nos campos educacionais e que trazem o paradoxo da contemporaneidade, na medida em que apresentam a falsa ideia/sensaçáo de reproduçáo, mas que materializa fortemente a impossibilidade de sua repetiçáo. Por mais que proclamemos, em alto e bom som/tom/signos, que não mais se pode persistir nas chamadas práticas tradicionais - em alusão ao espectro que ronda as açóes e espaços educacionais -, o que temos de fato é a sua morte. Não há mais o que chamaríamos de educação/abordagem tradicional (MIZUKAMI, 1986), por mais que alguns educadores insistam em manter viva a sua chama, até mesmo quando, como estamos fazendo aqui, criamos espaços de alusão à sua existência ou não.

Diante de um cenário cibercultural, de uma cultura digital e em rede que reconfigura e libera os polos de emissão e recepçáo, inserindo os sujeitos actantes, como quer Latour (1994), como parceiros, colaboradores e cocriadores de informaçôes, conhecimentos, recursos e relacionamentos, parece-nos impróprio pensar e persistir numa educação centralizada (e centralizadora) no docente e descolada do estudante.

Mas isso ainda existe, pode-se dizer. A educação tradicional não morreu, diriam outros. Conhecemos/convivemos com vários educadores e escolas que são "tradicionais", gritariam tantos!

De forma muito sucinta, resgataremos as características da educação tradicional, de modo a elucidar as ideias aqui apresentadas em relaçáo à sua morte. Dentre as premissas deste tipo de abordagem, destacamos algumas das mais debatidas (BRUNO; PESCE; BERTOMEU, 2012): a) a existência de estudantes disciplinados e 
passivos; b) o acesso às informaçóes e conhecimentos entendidos como privilégios (verdades irrefutáveis) dos docentes; c) o absoluto desprezo pelas experiências e saberes dos estudantes, compreendidos como "tábulas rasas". Estes três pontos são suficientes para decretarmos a morte do que foi, até então, denominado de tradicional.

Sabemos que o cenário educacional não é único e que nele existem tanto educadores cujas práticas são mais centralizadoras quanto os que buscam açóes de parceria e colaboração. Porém, ainda que tenhamos aqueles que persistem no apego às práticas centralizadoras, há que se considerar que os estudantes não são (e nunca foram) passivos, mas ativos e participativos; as informaçóes e os conhecimentos estão acessíveis em múltiplos espaços e suportes e podem ser consumidos e produzidos por todas as pessoas; as experiências e os saberes dos estudantes inserem-nos no processo educacional como interatores, o que colabora para que, com seus conhecimentos e acesso às informaçóes socializadas em dispositivos plurais, pratiquem a educação de modo colaborativo.

Portanto, a morte da centralidade do professor é fato e as tentativas para que tais práticas permaneçam têm sido desmanteladas, uma a uma, ainda que as 'ritalinas' se coloquem como pedras no meio do caminho.

Se o processo educacional implica diversos sujeitos sociais (professores, estudantes, gestores, comunidade) e tantos recursos, estratégias, políticas etc., como se pode ainda insistir que é possível praticar uma educação tradicional, cujo protagonismo se concentra no sujeito-professor?

No oroboro da educação tradicional, a cobra ou o dragão sempre buscam a repetição do mesmo, mas o que conseguem é, tão somente, morder a própria cauda: provocar dor.

Vejamos algumas das vertentes de educação. Segundo o dicionário Houaiss (2001), educação é entendida como "aplicação dos métodos próprios para assegurar a formaçáo e o desenvolvimento físico, intelectual e moral de um ser humano". Tal significação para a área das ciências sociais é insuficiente, mesmo que alguns estudos apresentem contribuiçốes interessantes a respeito dos termos educar e educação. Ainda a respeito do conceito de educaçáo: Brandão (2003) compreende-o como uma das invençóes culturais dos grupos sociais; para Libâneo (2000), seria uma prática social, enquanto Ordoñes (2005) associá-lo-ia a um fator de produção, um instrumento indispensável para o desenvolvimento social; já Saviani (1984) define-o como um fenômeno para a comunicação humana entre pessoas livres. Freire (2000, p. 89), por sua vez, provoca-nos a compreender que "a educaçấo é sempre uma certa teoria do conhecimento posta em prática, é naturalmente política, tem que ver com a pureza, jamais com o puritanismo e é em si uma experiência de boniteza”. 
A educação freireana, portanto, assume caráter amplo e inclusivo, sendo associada a uma teoria do conhecimento que reconhece que este processo não se dá sem o outro. Destarte, a educaçáo, como desenvolvemos no tempo hodierno, inexiste sem o outro, pois é por meio da relação com o outro que nos desenvolvemos. Somos e nos educamos na relação de nossas dimensóes biológica, psico-socio-cultural, afetiva e cognitiva. Pensar uma educação nesta perspectiva incita-nos a concebê-la em seu caráter onto e filogenético, para além do espaço formal. Não há mais um momento ou espaço específico para que a educação ocorra, pois ela faz parte do devir humano.

Nessa direção, as docências produzidas em meio à cultura digital e em rede dificultam a existência do que temos adjetivado no processo educativo como o "mais do mesmo". A reprodutibilidade é colocada em questão e perde adeptos e territórios, pois os espaços de aprendizagem foram ressignificados, redimensionados e "restaurados". É cada vez mais difícil persistir e ratificar propostas educacionais que desconsiderem a potência que as tecnologias atuais possuem, bem como as transformaçôes sociais que, junto e por meio delas, vêm ocorrendo.

$\mathrm{O}$ que podemos pensar a respeito dos processos formativos neste cenário? As formaçôes docentes desenvolvidas têm atendido a tais demandas top seculares? Está claro que o docente ou o licenciando é um adulto e, do mesmo modo, temos ainda persistido em formaçóes docentes fragmentadas: adultos que formam outros adultos, de forma prescritiva, algumas vezes propositiva, mas pouco vivencial e experiencial.

Paulo Freire (2000, p. 96) apresenta-nos uma reflexão crítica a respeito das transformaçôes pelas quais passamos nas últimas décadas, no que tange à educação do adulto, protagonista dos processos formativos, no campo das licenciaturas e dos programas de formaçáo continuada de docentes: "a educaçáo de adultos hoje, como a educaçáo em geral na perspectiva progressista, tanto quanto ontem e por novas razóes também, tem de continuar lutando contra as ideologias fatalistas [...] a necessidade da certeza de que mudar é difícil, mas é possível”.

Como as pesquisas acerca da educação e da aprendizagem de adultos são relativamente recentes, resgataremos algumas correntes ideológicas que influenciaram a área, de modo a problematizarmos este processo. Federighi e Melo (1999), por exemplo, apresentam duas abordagens:

- Neoliberal: sob influência de Knowles (1970), o foco incide sobre a igualdade de oportunidades, cuja ênfase é dada à aprendizagem (entendida como fenômeno de ordem psicológica), à responsabilidade individual pelo próprio desenvolvimento e à educação, tida como fator decisivo para oferecer melhores condiçóes a todos na sociedade;

- Crítico-radical: sob a influência de Gramsci (1976) e de Freire (1987), a 
educação contínua é vista como indutora da promoção de mudanças estruturais nos processos educativos, à luz da dimensão interativa e transformadora, rumo à contra-hegemonia, agregando todos os movimentos sociais.

Em complemento, os autores destacam as teorias que estudam o processo de aprendizagem de adultos, com duas fortes tendências:

1) a que estuda o processo de aprendizagem a partir das funçôes e estruturas internas do indivíduo, na fase adulta e ao longo da vida, tendo como representantes Rogers (1961), Maslow (1954) e Perls (1969), da psicologia humanista, que amparam o modelo proposto por Knowles (1970). Nesta abordagem, o vértice é o autodesenvolvimento do indivíduo, sendo a educaçáo de adultos considerada como um dos meios para facilitar o desencadeamento deste processo;

2) a que se preocupa com a complexidade individual e coletiva deste processo, identificada como teoria crítica. A partir de uma abordagem interdisciplinar, preocupase com as dimensóes socioculturais e históricas dos sujeitos, tanto individual quanto coletivamente. A educação para o sujeito, nesta vertente, objetiva levar o chamado sujeito histórico a se transformar e a transformar o contexto social pelo processo de conscientizaçáo. Tendo como um dos representantes principais Paulo Freire, que desenvolveu o conceito de conscientização, nesta tendência, a aprendizagem é percebida por sua dimensão transformadora, social. Tais pontuaçôes operam ao sinalizar que, nos processos formativos para e com a docência na contemporaneidade, coexistem as duas abordagens e tendências.

As açôes formativas colaborativas, colegiadas, integradas e mediadas por tecnologias digitais e em rede, ou seja, aquelas que se tratam de adultos colegiadamente em formação, com experimentaçôes de docências que horizontalizam as relaçôes entre formadores e estudantes que, por seu lado, interagem de modo colaborativo, como produtores do conhecimento, viriam ao encontro da segunda abordagem/tendência. Entretanto, é na primeira (neoliberal e voltada à psicologia humanista) que as açóes para e com a docência têm tido maior apelo formativo, por meio de cursos e programas de 'capacitação' para a docência ou da utilização de recursos e/ou estratégias. Nesta abordagem, ideias, cursos e programas formativos focalizam o objeto, com práticas que proclamam discursos críticos, mas praticam a instrumentalização, insistindo na manutenção do gap entre docentes e discentes, mesmo que mediados pelas tecnologias digitais e em rede.

Com esse tipo de formação, vemos discursos inflamados em prol do desenvolvimento do olhar crítico dos estudantes, integrado com práticas que se manteriam na centralidade do processo de docência no professor e também na 
utilização de recursos e estratégias didáticas que prometem revolucionar as salas de aula. Dito de outro modo, discursamos e prescrevemos ideias, por meio da segunda abordagem/tendência, mas a prática formativa acaba jazendo sobre a primeira opçáo. Disso resultam formaçôes prioritariamente (e por vezes exclusivamente) enraizadas na teoria e em descompasso com as experiências de docência equivalentes às propostas propagadas. Criamos, assim, uma espécie de mantra representativo de uma imagem não transformativa do oroboro, que se mantém para perpetuar o "mais do mesmo", segundo a qual, mudando-se os recursos, mudam-se também as práticas.

Por outro lado, a potência do oroboro, que carrega em si a mudança, abriria um canal para o ponto fulcral desse processo: a transformação de ideias e concepçôes. Nas palavras da Profa. Inês Teixeira ${ }^{1}$, em uma de suas falas proferida em mesa redonda, " $a$ gente não ensina o que sabe, a gente ensina o que (se) é”. As práticas não se distanciam das teorias. Entretanto, não podemos destas prescindir: é preciso desvelar quais são as teorias que sustentam/fundamentam as nossas práticas docentes.

\section{A cultura digital e em rede: desdobrando ideias para a prática do desapego}

Definitivamente a cultura digital e em rede vem transformando as relaçôes do ser humano com o mundo, com o outro e consigo. De várias formas e em lugarestempos diversos, esses pontos vêm sendo tocados e debatidos. No campo da Educação, por meio de movimentos que dançam melodias permeadas por manifestaçôes nos distintos espaços sociais, com ou sem bandeiras, dentro ou fora das/nas redes (online e ou presenciais), os debates acirram vozes que buscam compreensóes, acontecimentos, ousadias e transformaçóes.

Estamos vivendo e produzindo uma Educação Híbrida (BRUNO, 2013, MATHEOS, 2014) que, mais do que integrar modos online e presencial, maximiza as possibilidades de produção e a coexistência de ideias, espaços, cidades, movimentos e tempos, fundamentalmente criados por seres humanos, em um movimento ao mesmo tempo singular e plural. Nos tempos atuais convivem em cada um de nós ideias conflitantes, narrativas dissonantes, percepçóes multissensoriais, e tal cenário possibilita certa ética do paradoxo. Os contextos apresentam-se de forma híbrida, e na Educação não é diferente.

Santaella (2010) compreende o hibridismo como a integraçáo dos "espaços físicos de circulação" aos "espaços virtuais e informação". Notadamente com o sentido de misturar, de mesclar, uma Educação é híbrida, na medida em que articula espaços e tempos, modos diversos de comunicação e relacionamentos, diferentes componentes 
de acesso a informações, convergência de mídias e tecnologias, de modo a promover múltiplas possibilidades para a construção e para a produção do conhecimento. As conexóes e as redes online assumem-se como fios condutores-promotores de relaçóes, ideias, percursos e de produçóes coletivas. O termo "online" tem seu sentido ampliado e se mistura à ideia de rede. Online não é uma tradução fria e limitada do "em linha" ou de conectividade, mas incorpora sentidos para além disso tudo: em rede, em conexáo, com todos, ligado (BRUNO, 2011).

As redes sociais digitais, por sua vez, criam múltiplos desenhos e conexôes. Não se articulam por meio de nós ou laços, de pontos ou correntes, mas de rizomas. Como diriam Ferrari e Fernandes (2014, p. 40), "as redes sociais em geral são a encarnação possível da alucinação consensual do ciberespaço original de Willian Gibson em Neuromancer" - em alusão à visionária obra do autor, publicada originalmente em 1984 (GIBSON, 2008), em que cunhou a expressão ciberespaço e "previu" a era da informação, antes mesmo da Internet.

Potencialmente, as redes sociais digitais encontram-se grávidas de possibilidades e, dentre elas, destacam-se as redes rizomáticas, que coexistem, na ética do paradoxo do mundo contemporâneo, com as redes arbóreas (BRUNO, 2010). Ambas mesclam-conectam pessoas, informaçôes, produtos, mas, em convergência com a compreensáo do sentido e do significado de Internet pontuada por Ferrari e Fernandes (2014), assumem formas, tipos e formatos de cada povo, de cada grupo, de cada cenário/contexto. Se mais abertas, flexíveis e plásticas, como as rizomáticas; ou fechadas, limitadas e fixas, como as arbóreas, são as pessoas e seus usos quem as adjetivaráo, com o uso que delas fazem.

Tal qual a ideia de fronteira, trazida por Augé (2010, p. 25), de que "as fronteiras não se desfazem jamais, elas se redesenham”, as redes sociais atuais, em seus múltiplos movimentos e desenhos, associam-se ao que Freire (2002) já sinalizava sobre a consciência da incompletude e do inacabamento humanos. Redes em si, Internet por si, criam-se pelos actantes em ação. É nos espaços intersticiais produzidos em rede, que os seres hoje podem se educar. Ignorar que é neste cenário que vivemos e nos (trans)formamos e que, portanto, modificamos as formas de relação com tudo e todos, tem causado sérios danos à educação de nossas escolas/estudantes/docentes.

Se o cenário é prenhe de possibilidades, é nas dobras desses processos educacionais que as práticas emergem e se destacam como inovadoras, por produzirem/carregarem o gérmen da mudança. São açôes educacionais e acadêmicas que rompem com as prescriçôes criticadas anteriormente e ratificam as possibilidades emancipatórias de Freire (2000), e que, por sua vez, vão ao encontro do que Ranciere (2002), com seu Jacotot, ao afirmar que somente os emancipados podem emancipar os outros. 
Apresentaremos três experiências de formação docente que, no viés de Larrosa (2014, p. 128), intencionaram "'des-alunizar' os alunos, 'des-professorizar' os professores e 'des-disciplinar' as disciplinas”, no que foi possível, em acordo com os contextos. As três experiências tratam de processos implicados com a formaçáo de/com docentes, em meio à cultura digital. Por fim, traremos ainda uma proposta, em desenvolvimento, do que Bruno (2014) e seu grupo de pesquisa Aprendizagem em Rede - GRUPAR denominou de Percursos online, múltiplos, abertos e rizomáticos (POMAR), que traz as possibilidades para uma Educação Aberta e Híbrida.

A primeira delas (a ordem de apresentação destas experiências é aleatória) diz respeito a um processo formativo voltado a professores da UFJF², coordenado pela Coordenação de inovação acadêmica e pedagógica no Ensino Superior (CIAPES), em uma ação da Pró-Reitoria de Graduação da mencionada instituição. Em 2011, aquela coordenaçâo foi criada para atender às demandas emergentes, acerca da formação para a docência universitária. Tais exigências foram deflagradas especialmente diante do cenário sociotécnico latente nas sociedades contemporâneas, com forte apelo das tecnologias da informação e comunicação, digitais e em rede - fenômeno da Cibercultura, como tem sinalizado Santos (2014) - frente ao ingresso de um número significativo de professores na Universidade Federal de Juiz de Fora (UFJF). Vale destacar que as necessidades de formação continuada para a docência náo se devem exclusivamente às novas configuraçóes sociais e tecnológicas, pois há muito se evidenciam lacunas neste segmento da formação docente. É preciso recordar que a formação para a docência no ensino superior no Brasil é significativamente frágil, no que tange ao ensino em si, já que os cursos de Pós-Graduação (Stricto Sensu), que prioritariamente seriam responsáveis por tal processo, assumem o modelo americano e alemão, em que se favorece a pesquisa, em detrimento do ensino. Com isso, formamos pesquisadores e os habilitamos para a docência universitária sem, contudo, haver de fato açōes formativas voltadas para o ensino (PIMENTA; ANASTACIOU, 2002).

A CIAPES, coordenada pela Profa. Adriana Rocha Bruno entre 2011 e meados de 2014, criou o Programa Percursos Formativos, que teve como foco, num primeiro momento, os docentes ingressantes na universidade (em estágio probatório) e promoveu um "menu" diversificado, que buscou atender às demandas emergentes da multiplicidade de docentes e de cursos existentes naquele contexto. As demandas recorrentes relacionavam a docência às tecnologias digitais e em rede e, desse modo, foram oferecidos cursos e oficinas que intencionavam tratar a docência, a partir de uma visão plástica, aberta e em coerência com os propósitos de que a aprendizagem do adulto se dá por meio da experiência (KOLB, 1984; BRUNO, 2007; LARROSA, 2014). 
$\mathrm{Na}$ aprendizagem experiencial de Kolb (1984), a produção da experiência compreendida como a responsável pela aprendizagem, já que é a partir de sua transformação que o sujeito adulto aprende - ocorre de múltiplas formas ao longo da vida e, em cada momento, pode assumir nuances distintas. Ou seja, a experiência, que para Larrosa (2014) é o que nos passa, nos atravessa, nos acontece, não se processa da mesma maneira com todos os seres humanos. Isso se irmana com o que Bruno (2007) tem apontado como plasticidade, ou a potência de se fazer refazendo, de ressignificar/redimensionar o vivido, por meio de movimentos flexíveis que permitem trilhas com outros e novos percursos. Adensaremos mais estes pontos da experiência ao longo das apresentaçóes subsequentes.

A CIAPES, em seu Programa Percursos Formativos, promoveu junto aos docentes a experiência de criação de trilhas de aprendizagem. A ideia era que, a partir do Menu de cursos e oficinas disponibilizados, cada docente produzisse seu caminho (trans)formativo, de acordo com seus interesses e com a docência desejada. Partiu-se do desejado, da docência desejada, com os professores apontando suas necessidades, para a produçáo de percursos cujo roteiro era autoral: cada professor criou seu caminho para a docência.

Entre o primeiro e segundo oferecimento - de novembro de 2013 a junho de 2014 -, tivemos 434 certificaçóes de docentes. No primeiro oferecimento, foram realizados quatro cursos: 1) Docência no Ensino Superior; 2) Moodle I; 3) Moodle II; e 4) Tecnologias da informação e comunicação no Ensino Superior; além de cinco oficinas: 1) Videoaulas: do roteiro à disponibilização; 2) Produção de audiovisual na educaçáo; 3) Projeto de formação de professores através de ferramentas de som e produção de podcasts; 4) Projeto de material didático - módulo de contextualização; 5) CTS: um olhar sobre conhecimento e condição humana. No segundo oferecimento, foram desenvolvidos seis cursos, alguns realizados anteriormente e outros novos, criados a partir das demandas dos docentes no oferecimento anterior e no levantamento de demandas junto aos professores. Os cursos oferecidos foram: 1) Docência no Ensino Superior; 2) Estudo de Caso e outras estratégias práticas para o ensino superior; 3) Fundamentos teóricos da avaliação: refletindo sobre a prática, 4) Moodle I; 5) Moodle II; e 6) Tecnologia da Informação e Comunicação no Ensino Superior; além de cinco oficinas: 1) Podcast e recursos audiovisuais; 2) Imagens e narrativas: 'desconfiar das imagens', Harun Farock; 3) Plágio e direito autoral na docência no ensino superior; 4) Projeto de material didático - módulo de contextualização; 5) Utilização de artes e outros meios de apoio para o processo de ensino aprendizagem.

Estimava-se que os docentes perfizessem 120 horas de atividades formativas, ao longo de três anos. Todos os cursos/oficinas oferecidos foram semipresenciais 
(encontros presenciais no início e/ou no final) ou totalmente online. É interessante perceber que nos dois oferecimentos houve um número intenso de açóes formativas em que as tecnologias digitais e em rede assumiam lugar de evidência, sendo que esta solicitação partiu dos próprios docentes.

Ainda, todos os cursos e oficinas foram ministrados/produzidos por docentes da própria universidade, de diversas áreas de conhecimento, a maioria em parceria com estudantes de pós-graduação. Este aspecto veio corroborar a proposta de Larrosa (2014, p. 128) de “'des-alunizar' os alunos, 'des-professorizar' os professores e 'des-disciplinar' as disciplinas", pois colocou lado a lado docentes e discentes, em açóes de mediação partilhada (BRUNO, 2007, 2011), potencializadas pela dialogia digital (PESCE, 2003, 2012), quando partiu das emergências dos professores, em relação às docências e desenvolveu açôes de docências/discências não mais para professores, mas com os professores. Diferentemente do que se anunciou anteriormente, no continuum oroboro limitante/limitador, práticas docentes tendem a criar campos de imanência, quando cristalizam somente as experiências que dáo sentido aos conceitos e teorias estudadas. Desse modo, não mais se teoriza num primeiro momento e se exemplifica posteriormente, mas se experiencia e se teoriza em conjunto, com movimentos transformadores metaforizados pela alegoria do oroboro.

A segunda experiência traz as vivências de duas disciplinas ministradas no Curso de Pedagogia da UFJF: 1) Educação online: reflexóes e práticas (obrigatória); e 2) Arte e tecnologias na Educação contemporânea (optativa). Optamos por fazer recortes em açôes inovadoras destas duas disciplinas, de modo a atender aos propósitos ora apresentados. A partir de uma situação inusitada, ocorrida em 2012-2013, localizada na composição de horários para o oferecimento da disciplina 1 , que dividiu seus quatro créditos semanais, concentrando três deles num dia da semana, e um em outro dia. Esta hora/aula de cinquenta minutos foi ministrada às sextas-feiras, no primeiro tempo do período noturno - às $18 \mathrm{~h} 30 \mathrm{~min}$. Este cenário, a priori, causaria transtornos, pois são consensuais as dificuldades com as aulas noturnas, adensadas nos primeiros horários do último dia da semana, com estudantes que, atrasados, perdem o início das aulas e ainda apresentam o cansaço acumulado pelas atividades integradas, profissionais e acadêmicas, ao longo da semana.

Ocorre que, o que poderia se tornar um último estertor, renasceu em potência criativa na denominada "sexta.com". Esta aula era sempre uma surpresa e somente os estudantes que chegassem no horário teriam acesso a ela. A aura de mistério que envolveu esta parte da disciplina mostrou-se muito promissora e em poucas semanas a sala de aula estava lotada, com a participação intensa de todos. O que aconteceria nesta aula? Experiências, experimentaçóes. Em sua maioria apoiados por recursos 
tecnológicos, em composição com outros artefatos, tais como instrumentos musicais, contos e demais obras literárias, cases, vídeos, performances, fotografias etc., essas aulas promoviam, em certo sentido, experiências fronteiriças (AUGÉ, 2010, LARROSA, 2014) e também a transformação da sala de aula em um "não-lugar" - como quer Bauman (2003) -, com "todos em constante criação e com um tempo que transcende o relógio, um tempo 'tagueado'... esse novo 'não lugar' temporal” (FERRARI; FERNANDES, 2014, p. 43). É evidente que o não lugar é também um lugar, mas é também mais que um lugar, pois rompe com a espacialidade, com as delimitações de fronteira, com a condição arbórea que o viver em redes pode trazer na experiência coetânea. Mais uma vez vivenciamos possibilidades trazidas por Larrosa (2014, p. 28) de "'des-alunizar' os alunos, 'des-professorizar' os professores e 'des-disciplinar' as disciplinas", pois as experiências eram propostas, em um primeiro momento, pelas professoras (a disciplina é sempre desenvolvida em parceria com as/os orientandas/os de mestrado e de doutorado da professora responsável). A partir daí, os estudantes eram convidados a assumir e tomar para si a sexta.com: seriam estes últimos os promotores, os disparadores de outras experiências para todos, nos encontros futuros. Como desdobramento, a disciplina tornou-se virtualmente "obrigatória" nos oferecimentos subsequentes, configurando-se em segundas.com, terças.com etc.

Vivenciou-se a mediação partilhada, em meio ao hibridismo que, sem rotular ou delimitar os espaços de aprendizagem (dentro/fora, online-a distância/presencial, lugar/não lugar etc.), refletiu, na prática (ou na açâo), a capacidade transformadora que podem ter as ambiências pedagógicas, quando esgarçadas, alargadas, distendidas. São experiências que mudam a visão restritiva da "sala de aula": qualquer espaço-tempo constitui lugar para a aprendizagem experiencial, o que reconfigura, por exemplo, as cidades e o mundo como salas de aula.

Santos (2014) situa o poder que os dispositivos móveis possuem, como aparatos de convergência, dando acesso rápido a mídias e tecnologias que facilitam a produção de práticas e a experiência a qualquer momento e em qualquer lugar. É por tudo isso que a cultura digital e em rede, se utilizada a partir da premissa defendida no presente texto, pode fomentar experiências inovadoras. Não pelos recursos ou estratégias, mas pela experiência de interaçáo, comunicação, produção coletiva e colaborativa: são tais experiências que atribuem (outros) sentidos ao vivido por meio da práxis.

Nessa direção, importa ressaltar certa distorção sofrida pela Didática (como disciplina), cuja compreensão viu-se encarcerada em uma abordagem restritiva, porque instrumental, procedimental e prescritiva da atividade docente: foi reduzida a um punhado de recursos e estratégias. Entretanto, este campo de estudos da Educação possui pelo menos seis dimensóes: etimologia, significados, conteúdos, definiçóes, 
objeto e metateoria. Os recursos e estratégias - ações metodológicas - são parte de uma das dimensóes - os conteúdos. A redução dessas dimensões que compóem o campo da Didática provocou um comprometimento significativo dos processos formativos para as docências (BRUNO, 2007).

De maneira similar, na disciplina 2 (ministrada pela Profa. Adriana Bruno em parceria com a Profa. Olga Egas) as professoras responsáveis iniciaram o redimensionamento da sala de aula, ampliando seu campo de atuaçáo e expandindo ao máximo. Iniciando com caminhadas fotográficas pela Faculdade de Educação - a depuraçáo do olhar minucioso, de detalhes -, seleção e tratamento de imagens, composições com trilhas sonoras e utilização de recursos para socialização dessa experiência, passando pelo cinema, teatro de sombras, produção de vídeos (curtametragem), produção de memoriais criativos, experimentação no jardim sensorial, dramatizaçôes, danças e ensaios fotográficos em estúdio, culminando numa Mostra/Sarau cultural na última semana de aula - tudo agenciado, registrado, compartilhado, socializado e debatido com o uso do Facebook como apoio às aulas -, esta disciplina produziu efeitos inesperados nas estudantes, que relataram e expressaram transformações pessoais, somente viabilizadas pelas experiências, pela aprendizagem experiencial integradora preconizada por Kolb (1984) e Bruno (2007). Atribui-se os resultados transformadores das experiências produzidas por todos (docentes e discentes) nessas duas disciplinas, ao trabalho com todas as dimensôes da Didática, e não por sua instrumentalização. Além disso, foram os dispositivos móveis que viabilizaram a maioria das produçôes, pois boa parte das experimentaçóes se deu pelo uso de celulares e smartphones. A mobilidade e a ubiquidade vivenciadas, e não apenas teorizadas, oportunizaram o entrelaçamento teórico-prático.

Por fim, a terceira experiência realizou de forma ousada o tratamento final dos dados produzidos em uma pesquisa interinstitucional, denominada UCA BASC - em referência à Pesquisa: Gestão e práticas pedagógicas no âmbito do programa UCA: desafios e estratégias à consolidação de uma política pública para a educação básica. Para o desenvolvimento do relatório final da pesquisa, que envolveu três universidades públicas brasileiras - Universidade Federal da Bahia (UFBA), Universidade Federal de Santa Catarina (UFSC) e Universidade Estadual de Santa Catarina (UDESC) - e investigou experiências docentes e discentes de escolas dos dois Estados (Bahia e Santa Catarina) com o Projeto Um Computador por Aluno (UCA), os docentes responsáveis pela investigação promoveram um evento em que foram convidados pesquisadores externos (que náo possuíam vínculo ou relação direta com o foco da pesquisa), para atuarem como intercessores críticos da investigação em pauta. 
O arrojo com que os pesquisadores que coordenaram este processo assumiram, ao desnudar a pesquisa e seus desdobramentos para que leitores estrangeiros atuassem como colaboradores (comentadores) e, por conseguinte, coautores das análises e interpretações empreendidas na pesquisa, sinalizou as contingências múltiplas que um estudo de campo rigoroso pode alcançar. Mais do que proposiçôes ou prescriçôes sobre as nuances que as pesquisas em Ciências Humanas envolvem, esse evento materializou o que pode ser uma pesquisa colaborativa por meio da experiência, no que toca a resultados práticos. A criticidade e a parceria foram levadas à máxima potência. Nesse contexto, foram proporcionadas experiências em diversas direçôes. Experiências rizomáticas, poderíamos dizer. Integrou-se os sujeitos da investigação, os pesquisadores das universidades, os convidados (comentadores) e ainda os estudantes de cursos de graduação e pós-graduação para, juntos, durante três dias, vivenciarem e produzirem experiências; dados outros de experiências. Experimentaçóes disparadas por meio do encontro plural sobre os usos e as políticas implicadas no UCA, em cenários singulares.

Se por um lado os dados revelaram as contradiçóes, os paradoxos, as possibilidades e implicaçóes que uma política como essa propicia, por outro lado mostrou que os cenários se modificam com o acesso, mesmo que muito precário, às tecnologias - no caso, o laptop individual. Ao oferecer mobilidade e interiorização da ubiquidade aos estudantes, extensiva a toda família/comunidade, o UCA criou necessidade e deflagrou desejos e caminhos até então desconhecidos e sem volta para todos os implicados. Entretanto, as fragilidades do projeto, de uma política que ratifica a abordagem neoliberal apontada anteriormente, explicitaram algumas lacunas conhecidas por muitos pesquisadores e estudiosos da área, como Pesce (2013), promovendo um déjà $v u$ angustiante, sintetizado na precariedade dos recursos disponibilizados para o desenvolvimento do UCA, com computadores frágeis e acesso à Internet muito instável. Os dados e o evento evidenciaram que os pesquisadores, por meio da compreensão-ação de que a pesquisa é também um processo interventivo, atenuaram e, em muitos casos, sanaram as intempéries vivenciadas pelos sujeitos da pesquisa e pelas escolas em si. Ainda assim, uma questão precisa ser posta: afinal, onde nós, formadores de docentes e pesquisadores, estamos errando? Qual a razão para o gap entre os saberes e práticas docentes e discentes? Por que existem docentes que ainda persistem em fazer uso exclusivamente pessoal das tecnologias digitais e em rede, em detrimento do pedagógico/docente?

Até quando teremos falas que, de forma recursiva, gritam para que políticas e açóes pedagógicas atendam de fato às necessidades das escolas e dos docentes e discentes?

Os relatos a seguir mostram ainda o distanciamento, o fosso entre docentes e discentes: 
O que eu percebia era que os professores estavam ficando meio que desesperados, desistindo, porque os alunos queriam outras coisas, o professor está lá na frente e eles estão assistindo outro video, que nem sei como eles baixavam, eles têm essa capacidade também, fazer o que a gente náo consegue fazer. (Professor 2, da escola Q).

Eu acho melhor ter o computador dentro da sala de aula... porque não ficam aquelas pessoas chatas que ficam te auxiliando, te controlando. (Estudante 4, do $7^{\circ}$ ano, da escola Q).

As experiências, como quer Larrosa (2014), envolvem interrupção, açóes com vagar, como: parar para escutar, parar para olhar, parar para pensar, para observar, sem pressa. Por isso o alerta do autor sobre a dificuldade de se experienciar. O sujeito da experiência não se assujeita, ele é passivo na medida do permitir-se vivenciar, "exposto".

Mas esse sujeito da experiência, para não se submeter, precisa ser autônomo. Numa sociedade em que predomina o cultivo à heteronomia, ser e assumir a autonomia assoma cada vez mais utópico. As mesmas forças/condições disponíveis na cultura digital e em rede para o exercício efetivo da experiência e da autonomia, de forma centrípeta, trabalham para que persista a existência de sujeitos heterônomos. Assim, compreendendo que a heteronomia, na fase adulta, potencializa a cultura de dependência e de submissão (BRUNO, 2007), o confronto com este cenário pode se dar por meio da Educação aberta e híbrida.

Uma educação híbrida só terá sentido se também for aberta, pois o hibridismo deve ser assumido para além da mistura, da mescla, mas, como preconiza o campo da comunicação, deve trazer a possibilidade de articulação e integração de pessoas, ideias, recursos e tecnologias, com movimentos plásticos e fluidos. O híbrido, desse modo, não será confundido com o conceito advindo da biologia, para o qual híbrido pode ser sinônimo de infértil. Em composição, a ideia de abertura buscaria, de forma coerente, alicerces na abordagem crítica, libertadora.

$\mathrm{Na}$ busca da coerência epistemológica e prática freireanas, em meio ao enfrentamento dos conceitos estudados e debatidos ao longo das pesquisas por nós desenvolvidas em quase duas décadas, apresentamos o POMAR, como prenúncio do devir de experiências e docências na contemporaneidade.

\section{Temas e dilemas educacionais contemporâneos: campo de imanência nas/com as docênciaS}

Cotidianamente, o campo educacional depara-se com temas e dilemas que afetam e colocam em xeque as ideias e crenças que acompanham os processos 
formativos humanos. São tantos que seria impossível listá-los de uma vez. De múltiplas formas e em diferentes situaçóes debatemos, criticamos e refletimos sobre as questóes e os elementos encontrados na associação entre docência, discência e pesquisa. Há tempos que as mídias deixaram de ser vistas como meros condutores ou viabilizadores de ideias, dados, informaçôes e produçóes. A cultura digital e em rede tem revelado que a cibercultura modifica o ser, na sua relaçáo com o mundo e não pode se traduzir apenas como meios (MCLUHAN, 1969).

É oportuno, então, para além das proposições e/ou prescrições que nos (con)formaram até o momento, sinalizarmos percursos e trilhas, para que as transformaçóes se evidenciem e mostrem alternativas. As três experiências compartilhadas por nós apresentaram pistas que explicitaram açóes de docência e pesquisa na educaçẫo, integrando teorias e práticas, porém podemos avançar ainda mais. Há muito por fazer, pensar e experienciar. Note-se que é a prática do desapego que favorecerá as transformaçôes. É com o desprendimento de "convicçôes", ideias, práticas, conceitos e "verdades" que as mudanças pedagógicas estão a emergir. Tal quadro se evidencia nas açóes transgressoras tratadas em filmes-documentários recentes, produzidos de forma independente e que apresentam açóes de docência que rompem com o que está(va) cristalizado há pelo menos dois séculos. É o caso do documentário argentino La Educación Prohibida 3 (A Escola Proibida), de 2012, ou do brasileiro Quando sinto que já seí, lançado em julho de 2014. Além de assumidamente inovadores, esses documentários foram produzidos em consonância com as possibilidades advindas da cultura digital e custeados por contribuiçóes abertas e voluntárias em redes digitais (modelos de financiamento coletivo mais conhecidos como crowdfunding).

Essas cocriações, inimagináveis até há pouco tempo, convergem para o que Simon Harel (2005) denomina "braconagem". Sem tradução para o português, de forma livre esta palavra foi "aportuguesada" pelo tradutor, e seu significado está próximo da caça ou pesca ilícita. Conceito sequestrado para ser ligado aos propósitos da Educaçáo aberta e híbrida que alicerçam o POMAR (BRUNO, 2014), tratado adiante, a braconagem dá o sentido desejado aos movimentos transgressores pretendidos na proposta, pois questiona as intençóes do que é lícito e provoca os educadores a serem braconeiros, ou seja, duvidarem, ousarem e romperem com o dito, o pensado e o falado; buscarem suas (co)autorias; habitando, "invadindo" espaços-tempos de forma autônoma e consciente.

Convergindo com tal entendimento, trazemos à baila as ideias de Pretto (2012), que advoga em favor do conceito de "professores autores em rede", inserindo-o em um cenário político que defende a produção colaborativa, a abertura de dados de pesquisa, a 
disseminação de software livre e de código aberto. O conceito de professores como autores em rede implica uma miríade de princípios e açóes, tais como: assumir a produção compartilhada por pares e remixadas; conceber a escola, para além de espaço de consumo de informaçóes e os professores da educação básica como protagonistas desse processo, em uma dinâmica que busque, cada vez mais, a autonomia docente, mediante aproximação de dois campos imbricados: docência e pesquisa. Nessa perspectiva, o autor situa os materiais didáticos não como definidores dos percursos formativos, mas como contribuintes, no que ele denomina ecossistema pedagógico (escola, comunidade escolar, redes de informação e comunicação). Do mesmo modo, o autor assume a ideia de que a produção de material didático deva voltar seus olhares para as culturas local e global. Em suma, situa professores e alunos como produtores de conhecimento e cultura.

As pesquisas empreendidas no Grupo de pesquisa Aprendizagem em Rede (GRUPAR) gestaram a ideia de POMAR. Não se trata de um ambiente de aprendizagem, mas de concepçóes sobre os processos de aprendizagem e docências contemporâneos. O POMAR pode ser desenvolvido usando as tecnologias disponíveis, mas, para além da utilização dos estruturantes tecnológicos, o que realmente importa é convergir para as premissas da Educação Aberta e híbrida em si. Estamos falando de percursos e náo cursos, pois se trabalhamos para que o sujeito seja autônomo, é ele quem tem todas as condiçôes de criar suas trilhas de aprendizagem e de formação. É online porque compreende a potência das conexôes, das redes sociais e dos dados gerados, produzidos e consumidos. É múltiplo porque plural: cria campos de agenciamentos em graus de profundidade e relaçáo entre pessoas e com as temáticas e estudos socializados. É aberto porque fomenta rupturas com qualquer tipo de reducionismo, pois sua condiçấo crítica sugere que os compartilhamentos sejam de todos para todos, sem restriçôes e sem pré-requisitos, além de serem abertos também para retroalimentaçôes das temáticas, para construçôes de outras temáticas afins e mesmo de outros POMAR. Somente o desejo de conhecer, relacionar-se e aprender devem mover as pessoas em rede. E é rizomático porque, congruente com a plasticidade do processo de autonomia e experiência, a fluidez e a dinamicidade, a interatividade e a não linearidade precisam estar presentes.

Criar POMAR tem se materializado em experiências de docênciaS singulares e plurais. Por serem coletivos, colaborativos, coautorais, abertos e híbridos, os POMAR permitem-nos experiências que implicam produçóes colegiadas e particularmente inacabadas, pois tais percursos são abertos e os sujeitos-usuários, em redes, são, se assim desejarem, coautores. 
É a ideia de braconagem que nos permite desenvolver o POMAR, pois não admite cerceamentos: esses percursos não podem ter "donos" ou controles, pois sua abertura deve ser irrestrita.

Enfim, é notável a concepção de docênciaS trazida neste artigo. Em concordância com o que já apontava Novoa (1991) sobre o desenvolvimento da profissão docente, que aglutinou, desde o século XVIII, elementos vários aos especialistas que se dedicavam ao ensino, mas complexificando, ampliando e atualizando a docência na contemporaneidade, admite-se que este termo está muito além das atividades pedagógicas, como queria Libâneo (2005). Isso porque as docências, nos tempo-espaços atuais, integram às atividades pedagógicas as ações de pesquisa, além das literacias - como tem sido assumida na área da Comunicaçáo -, conhecimentos e práticas com as mídias e as tecnologias digitais e em rede incorporadas às ações múltiplas, críticas, (co)autorais no campo educacional (formal ou não).

Sendo assim, ser docente contemporâneo implica, dentre outras atitudes: estar no mundo, ser um sujeito que produz e consome cultura e materiais didáticos; relacionar-se de forma indisciplinar (CHASSOT, 2013) com e por meio dos recursos tecnológicos e midiáticos disponíveis; atuar como parceiro de seus colegas e dos estudantes com os quais encontra; experienciar e experimentar, sabendo que é por meio do entrelaçamento da teoria com a prática que isso será possível.

\section{Notas}

${ }^{1}$ Mesa redonda no I Seminário da FACED-UFJF. Universidade Federal da Juiz de Fora. 24 a 28 de junho de 2013. Essas ações formativas para a docência no Ensino Superior são foco de investigação da Pesquisa "Formação Docente no Ensino Superior em tempos de Cibercultura: multiplicidade, coaprendizagem e educação online" - Eixo 1, coordenada pelo Adriana Rocha Bruno (UFJF) e financiada pela Fundação de Amparo à Pesquisa do estado de Minas Gerais (Edital Universal - 2013-2015).

${ }^{2}$ Disponível pelo endereço: <http://www.educacionprohibida.com/>. Acesso em: 12 dez. 2014.

${ }^{3}$ Disponível pelo endereço: <http://www.quandosintoquejasei.com.br/>. Acesso em: 12 dez. 2014.

\section{REFERÊNCIAS}

AUGÈ, Marc. Por uma antropologia da mobilidade. Maceió: EDUFAL, 2010. 
BAUMAN, Zygmunt. Modernidade Líquida. Tradução de Plínio Dentzien. Rio de Janeiro: Zahar, 2003.

BRANDÃO, Carlos Rodrigues. O que é Educação. São Paulo: Brasiliense, 2003.

BRUNO, Adriana Rocha. Aprendizagem do educador: estratégias para a construção de uma didática on-line. 2007. 257 f. Tese (Doutorado em Educação) - Pontifícia Universidade Católica de São Paulo, Sáo Paulo, 2007.

BRUNO, Adriana Rocha. Travessias invisíveis: plasticidade, diferença e aprendizagem em redes rizomáticas de formação de adultos educadores nos ambientes online. In: DALBEN, Angela et al. (Org.). Didática e prática de ensino: convergências e tensōes no campo da formação e do trabalho docente. Belo Horizonte, MG: Autêntica, 2010. v. 2. p. 171-196.

BRUNO, Adriana Rocha. A mediação partilhada em redes sociais rizomáticas: (des)territorialização de possibilidades para a discussão sobre o Ser tutor e a tutoria em cursos online. In: FONTOURA, Helena Amaral da; SILVA, Marco. (Org.). Práticas pedagógicas, linguagem e mídias: desafios à pós-graduação em Educação em suas múltiplas dimensôes. Rio de Janeiro: Anped Nacional, 2011. v. 1. p. 116-131. Disponível em: <http://www.fe.ufrj.br/anpedinha2011/ebook1.pdf>. Acesso em: 10 dez. 2014.

BRUNO, Adriana Rocha. Educação híbrida: múltiplas possibilidades para a aprendizagem contemporânea. In: SEMANA DE EDUCAÇÃO DA UNIFESP, 2., 2013. São Paulo. Anais... São Paulo: UNIFESP, 2013.

BRUNO, Adriana Rocha. POMAR (Percursos Online Múltiplos, Abertos e Rizomáticos): espaços de coproduçóes para as docências e aprendências. Simpósio Internacional de Educação a distância. 24 a 26/10/2014. Palestra proferida na Mesa redonda 2: "Pesquisa e produção do conhecimento em educação, tecnologias e linguagens". Programação disponível http://www.siedenped2014.ead.ufscar.br/ojs/index.php/2014/pages/view/programacao Acesso em 08 dez. 2014.

BRUNO, Adriana Rocha; PESCE, Lucila; BERTOMEU, João Vicente Cegato. Teorias da educação e da comunicação: fundamentos das práticas pedagógicas mediadas por tecnologias. Teias, Rio de Jnaeiro, v. 13, n. 30, p. 117-141, 2012.

CHASSOT, Aticco. Indisciplinaridade: para além da transdisciplinaridade. Blogue do Mestre Chassot, Porto Alegre, ano 7, 16 maio 2013. Disponível em: <http://mestrechassot.blogspot.com.br/2013/05/13-indisciplinaridade-para-alemda.html>. Acesso em: 2 dez. 2014. 
DELEUZE, Gilles. Lógica do sentido. São Paulo: Perspectiva, 2011.

FEDERIGHI, Paolo, MELO, Alberto. Glossário de educação de adultos na Europa. Barcelona: Associação Europeia para Educação de Adultos, 1999.

FERRARI, Pollyana, FERNANDES, Fabio. No tempo das telas: reconfigurando a comunicação. São Paulo: Estação das letras e cores, 2014.

FREIRE, Paulo. Pedagogia do oprimido. 17. ed. Rio de Janeiro: Paz e Terra, 1987.

FREIRE, Paulo. Pedagogia da indignação: cartas pedagógicas e outros escritos. São Paulo: Editora da UNESP, 2000.

FREIRE, Paulo. Pedagogia da Autonomia: saberes necessários à prática docente. 25. ed. São Paulo: Paz e Terra, 2002.

GRAMSCI, Antonio. Sobre Democracia Operária e outros textos. Lisboa: Ulmeiro. 1976. (Biblioteca Ulmeiro, n. 4).

GIBSON, Willian. Neuromancer. Tradução Fabio Fernandes. $4^{a}$ edição. Sáo Paulo: Editora Aleph, 2008.

HAREL, Simon. Braconagem: um novo modo de apropriação do lugar? Interfaces Brasil/Canadá, Rio Grande, RS, n. 5, 2005. Disponível em: <http://www.revistas.unilasalle.edu.br/index.php/interfaces/article/view/775>. Acesso em: 5 dez. 2014.

HOUAISS. Dicionário da Lingua Portuguesa. São Paulo: Instituto Antonio Houaiss; Objetiva, 2001. 1 CDROM.

KOLB, David A. Experiential Learning: experience as the Source of learning and development. EUA, New Jersey: Prentice Hall, 1984.

KNOWLES, Michael S. The modern practice of adult education: from pedagogyto andragogy. New York: Ass. Press, 1970.

LARROSA, Jorge. Tremores: escritos sobre a experiência. Tradução de Cristina Antunes e João Wanderley Geraldi. São Paulo: Autêntica, 2014.

LATOUR, Bruno. Jamais fomos modernos: ensaio de antropologia simétrica. Tradução de Carlos Irineu da Costa. Rio de Janeiro: Editora 34, 1994.

LIBÂNEO, José Carlos. Educação: pedagogia e didática. In.: PIMENTA, Selma Garrido (Org.). Didática e formação de professores: percursos e perspectivas no Brasil em Portugal. São Paulo: Cortez, 2000. 
LIBÂNEO, José Carlos Pedagogia e pedagogos, para quê? 8. ed. São Paulo: Cortez, 2005.

MCLUHAN, Marshall. O meio é a Mensagem. In: MCLUHAN, Marshall. Os meios de comunicação como extensöes do homem. São Paulo: Cultrix, 1969. p. 21-37. MASLOW, Abraham. Motivation and Personality. New York: Harper and Row, 1954.

MATHEOS, Kathleen. Educação híbrida: a chave de inovação nas universidades canadenses. In: REALI, Aline M. R.; MILL, Daniel (Org.). Educação a distância e tecnologias digitais: reflexôes sobre sujeitos, saberes, contextos e processos. São Carlos, SP: EdUFSCAR, 2014. p. 57-68.

MIZUKAMI, Maria das G. N. Ensino: as abordagens do Processo. São Paulo: EPU, 1986.

NÓVOA, António. Para o estudo sócio-histórico da gênese e desenvolvimento da profissão docente. Teoria \& Educação, Porto Alegre, n. 4, p. 109-139, 1991.

ORDONEEZ, Victor M. A educação fundamental no século XXI. In: DELORS, Jacques (Org). A educação para o século XXI: questóes e perspectivas. Tradução de Fatima Murad. Porto Alegre: Artmed, 2005. p. 155-171.

PERLS, Fritz. Ego, hunger and aggression. Nueva York: Random House, 1969.

PESCE, Lucila. Dialogia Digital: em busca de novos caminhos à formação docente em ambientes telemáticos. 2003. Tese (Doutorado em Educação) - Pontifícia Universidade Católica de São Paulo, São Paulo, 2003.

PESCE, Lucila. Formaçáo online de educadores: uma proposta dialógica. In: MATOS, Olivia; PESCE, Lucila (Org.). Educação e cultura midiática. Salvador: EDUNEB, 2012. v. 1. p. 129-153.

PESCE, Lucila. O Programa Um Computador por Aluno no Estado de São Paulo: confrontos e avanços. In: REUNIĀO ANUAL DA ANPED, 36., 2013, Goiânia. Anais... Goiânia: Editora da UFG, 2013. v. 1. p. 1-31.

PIMENTA. Selma G.; ANASTASIOU. Lea G. C. Docência no Ensino Superior. São Paulo: Cortes, 2002. v. 1.

PRETTO, Nelson. Professores autores em rede. In: SANTANA, Bianca; ROSSINI, Carolina; PRETTO, Nelson (Org.). Recursos Educacionais Abertos: práticas colaborativas e políticas públicas. Salvador: EDUFBA; São Paulo: Casa da Cultura Digital, 2012. p. 91-108. Disponível em:

<http://www.livrorea.net.br/livro/home.html>. Acesso em: 9 dez. 2014. 
RANCIÈRE, Jacques. O mestre ignorante: cinco liçôes sobre a emancipação intelectual. Tradução de Lílian do Valle. Belo Horizonte: Autêntica, 2002. ROGERS, Carl. On Becoming a Person. Boston: Houghton Mifflin, 1961. SAVIANI, Dermeval. Educação: do senso comum à consciência filosófica. 4. ed. São Paulo: Cortez; Autores Associados, 1984.

SANTAELLA, Lucia. A ecologia pluralista da comunicação: conectividade, mobilidade, ubiquidade. São Paulo: Paulus, 2010.

SANTOS, Edméa. Pesquisa formação na cibercultura. Portugal: Whitebooks, 2014. 


\section{Teaching in/with the contemporaneity: (trans) form- ing experiences through the digital and networked culture}

\begin{abstract}
This article discusses the teaching(S) (in the plural) in contemporary times, in the midst of digital culture and networked. The multiplicity, one of the hallmarks of today's world, calls all of us to the distortion of looks, maximizing perceptions, listens and smells, in an explosion of flavors, to the paradoxical experience in timeless and multi spatial dimensions. The diverse and plural coexist in a contradictory, complex and intriguing way. To talk/think about training processes, teaching and learning, in this context, it is necessary to capture and understand this movement in a plural sense. This context justifies the expression teaching in a plural, multiple dimension. To deal with a subject so vast and complex, the authors bring three points: 1) Oroboro: persistence/insistence of teaching apart from learning; 2) digital and networked culture: unfolding ideas to practice detachment; 3) issues and dilemmas as active field of possibilities in/with contemporary teaching(S). All these points are developed/discussed by researches conducted by the authors in recent years, together with the experiences of teaching $(S)$, handled by research on teaching practices created in co-authorship in cyber culture.
\end{abstract}

Keywords: Contemporary Teaching. Digital Culture. Experiences and Networks.

\section{Enseñanza en/con la contem- poraneidad: experiencias (trans)formadoras através de la cultura digital y en red}

\begin{abstract}
Este artículo aborda las enseñanza(S) en la contemporaneidad en medio de la cultura digital y en red. La multiplicidad, una de las características del mundo de hoy, llama a la distorsión de las miradas, percepciones, maximizando escucha y olores, a una explosión de sabores, a la experiencia paradójica, en dimensiones con característica atemporal y multiespacial. Lo diverso y lo plural coexisten de manera contradictoria, compleja y estimulante. Para hablar / pensar en procesos de capacitación, enseñanza y aprendizaje en este contexto, es necesario pensar de modo plural. Justifica, así, la expresión enseñanza(S), especialmente la letra $S$, plural, múltiple. Para hacer frente a un tema tan vasto y complejo, son presentado tres puntos de inflexión: 1) Oroboro: persistencia/insistencia aparte de la enseñanza; 2) la cultura digital y en red: se desdoblan ideas para practicar el desapego; 3 ) las cuestiones y dilemas como campo activo de posibilidades en/con enseñanza( $(S)$ contemporáneas. Todos estos puntos se desarrollan por medio de las investigaciones que fueron desarrolladas en los últimos años, articuladas a las experiencias de enseñanza(S) sobre las prácticas pedagógicas fundadas en coautoría en la cibercultura.
\end{abstract}

Palabras claves: Enseñanzas Contemporáneas. Cultura Digital. Experiencias y Redes. 
Adriana Rocha Bruno

E-mail: arbruno@gmail.com

\section{Lucila Pesce}

E-mail: lucilapesce@gmail.com

Recebido em: 15/12/2014 Aprovado em: 21/03/2015 
